\title{
Endplate calcification and cervical intervertebral disc degeneration: the role of endplate marrow contact channel occlusion
}

\author{
K.A. Tomaszewski ${ }^{1}$, D. Adamek ${ }^{2}$, T. Konopka ${ }^{3}$, R. Tomaszewska², J.A. Walocha ${ }^{1}$ \\ ${ }^{1}$ Department of Anatomy, Jagiellonian University Medical College, Krakow, Poland \\ 2Department of Pathology, Jagiellonian University Medical College, Krakow, Poland \\ ${ }^{3}$ Department of Forensic Medicine, Jagiellonian University Medical College, Krakow, Poland
}

[Received 19 May 2014; Accepted 3 August 2014]

Background: The aim of this study was to determine the fundamental relationships between cervical intervertebral disc (IVD) degeneration, endplate calcification, and the patency of endplate marrow contact channels (MCC).

Materials and methods: Sixty cervical IVDs were excised from 30 human cadavers. After sectioning the specimens underwent micro computed tomography (microCT) - from all images the number, calibre, diameter and distribution of endplate openings were measured using ImageJ. Next, the specimens were scored for macroscopic degeneration (Thompson's classification), and subsequently underwent histological analysis for both IVD and endplate degeneration (Boos's classification) and calcification.

Results. The study group comprised 30 female and 30 male IVDs (mean age \pm SD: $51.4 \pm 19.5)$. Specimen's age, macroscopic and microscopic degeneration correlated negatively with the number of MCCs $(r=-0.33-(-0.95) ; p<0.0001)$, apart from the MCCS $>300 \mu \mathrm{m}$ in diameter $(r=0.66-0.79 ; p<0.0001)$. The negative relationship was strongest for the MCCs 10-50 $\mu \mathrm{m}$ in diameter. Conclusions. There is a strong negative correlation between the number of endplate MCCS, and both macroscopic and microscopic cervical IVD and endplate degeneration. This could further support the thesis that endplate calcification, through the occlusion of MCCs, leads to a fall in nutrient transport to the IVD, and subsequently causes its degeneration. (Folia Morphol 2015; 74, 1: 84-92)

Key words: calcification, cervical intervertebral disc, degeneration, endplate, marrow contact channel occlusion

\section{INTRODUCTION}

The intervertebral disc (IVD) is the largest avascular structure in the human body [19] - in the lumbar spine some IVD cells can be up to $8 \mathrm{~mm}$ from the nearest direct blood supply $[1,19]$.

The IVD can be separated macroscopically into three different components. A centrally located gelatinous mass (the nucleus pulposus - NP) is enclosed in concentrically organised layers of collagen fibres (the inner and outer annulus fibrosus), which are framed, at the cranial and caudal ends of each disc, by hyaline-like cartilaginous end-plates forming a transition zone to the adjacent vertebral bodies [21]. The endplates are typically less than $1 \mathrm{~mm}$ thick, and while this varies considerably across the width of any single disc, they tend to be thinnest in the central region adjacent to the nucleus [6]. The endplates are identifiable from an early embryological stage and

Address for correspondence: Dr K.A. Tomaszewski, Department of Anatomy, Jagiellonian University Medical College, ul. Kopernika 12 31-034 Kraków, Poland, tel/fax: +48 1242295 11, e-mail: krtomaszewski@gmail.com 
have an osseous, as well as a hyaline cartilage component $[19,29]$. A network of microscopic blood vessels penetrates the endplates during development of the growing spine, principally to provide nutrition for the disc, before disappearing around the time of skeletal maturity [19]. After this point in development the mineralised portion of the endplate is penetrated only by marrow contact channels (MCC), through which capillary buds emerge. These capillary buds connect the trabecular spaces to the cartilaginous endplate, but do not penetrate into it [20]. Apart from a sparse vascular supply in the outer lamellae of the annulus, mature discs are almost totally dependent on diffusion of essential solutes across the endplates for nutrition and metabolic exchange [34]. In addition, several studies have shown that it is the central portion of the endplate that is responsible for the diffusion of the majority of nutritional substances $[22,24]$.

One of the primary causes of disc degeneration is thought to be failure of nutrient supply to the disc cells [32]. In vitro, the activity of disc cells is very sensitive to changes in extracellular oxygen and $\mathrm{pH}$ levels [10-12]. Disc cells do not survive prolonged exposure to low pH or glucose concentrations [9, 10]. A fall in nutrient supply that leads to a lowering of oxygen tension or of $\mathrm{pH}$ (a result of raised lactic acid concentrations) could thus affect the ability of disc cells to synthesize and maintain the disc's extracellular matrix and could ultimately lead to disc degeneration $[24,32]$. The pathway from the blood supply to the nucleus cells is hazardous because these cells are supplied almost entirely by capillaries that originate in the vertebral bodies, penetrate the subchondral plate and terminate just above the cartilaginous endplate [32]. Nutrients must then diffuse from the capillaries through the cartilaginous endplate and the dense extracellular matrix of the NP to the cells $[1,19]$. Nutrient supply to nucleus cells can be disturbed at several points. Factors that affect the blood supply to the vertebral body such as atherosclerosis [8], sickle cell anaemia, caisson disease, and Gaucher's disease [24] all appear to lead to a significant increase in disc degeneration. Finally, even if the blood supply remains undisturbed, nutrients may not reach the disc cells if the cartilaginous endplate calcifies [1, 13, $25,34]$. Intense calcification of the endplate is seen in scoliotic discs [33].

The above relationship has been proven for lumbar IVDs [1]; however it was not directly related to the degeneration of their endplates. When compared with lumbar disc degenerative disease, little is known about the degeneration of cervical IVDs and their endplates. Thus, the aim of this study was to determine the fundamental relationships between cervical IVD degeneration, endplate calcification, and the patency of endplate MCC.

\section{MATERIALS AND METHODS}

\section{Material acquisition}

Sixty cervical IVDs were excised from 30 human cadavers (at the Department of Forensic Medicine, Jagiellonian University Medical College), using the anterior approach, not later than $48 \mathrm{~h}$ post-mortem [17]. The material was excised in one block comprising vertebral bodies, IVDs, endplates and blood vessels supplying these structure, and wrapped in saline soaked gauze, vacuum-sealed to prevent dehydration, and kept at $4^{\circ} \mathrm{C}$ until micro computed tomography (microCT) scanning (on the same day). Excision started at the level of the lower half of the C4 vertebra and ended at the level of the upper half of the C6.

The study inclusion criterion was the ability to excise a section of the anterior spinal column (from the lower half of the C4 vertebra to the upper half of the (6), with the anterior and posterior longitudinal ligaments and blood vessels supplying the vertebrae. Study exclusion criteria were: (1) injury to the cervical spine, preventing from excising the required section; (2) previous cervical spine surgery; (3) receiving chemotherapy in the last 12 months; (4) previous radiation therapy to the perispinal region; (5) long-standing paralysis ( $\geq 6$ months); (6) ankylosing spondylitis.

\section{MicroCT scanning}

Before scanning each sample was unpacked from the vacuum-sealed container, and sectioned transversally at the middle of the $\mathrm{C} 5$ vertebral body. This produced two samples from each cadaver encompassing the IVD with its both endplates, surrounded from both ends by part of the vertebral bodies.

The samples were scanned using a microCT scanner (SkyScan 1172 N.V., Aartselaar, Belgium) (Department of Medical Physics, Institute of Physics, Jagiellonian University). The spatial resolution was set to $13.68 \mu \mathrm{m}$ per pixel. The shadow images were obtained using an X-ray source energy of $80 \mathrm{keV}$ using the $0.5 \mathrm{~mm}$ Al filter. The angular step between image acquisitions was $0.4^{\circ}$ and each image was averaged 

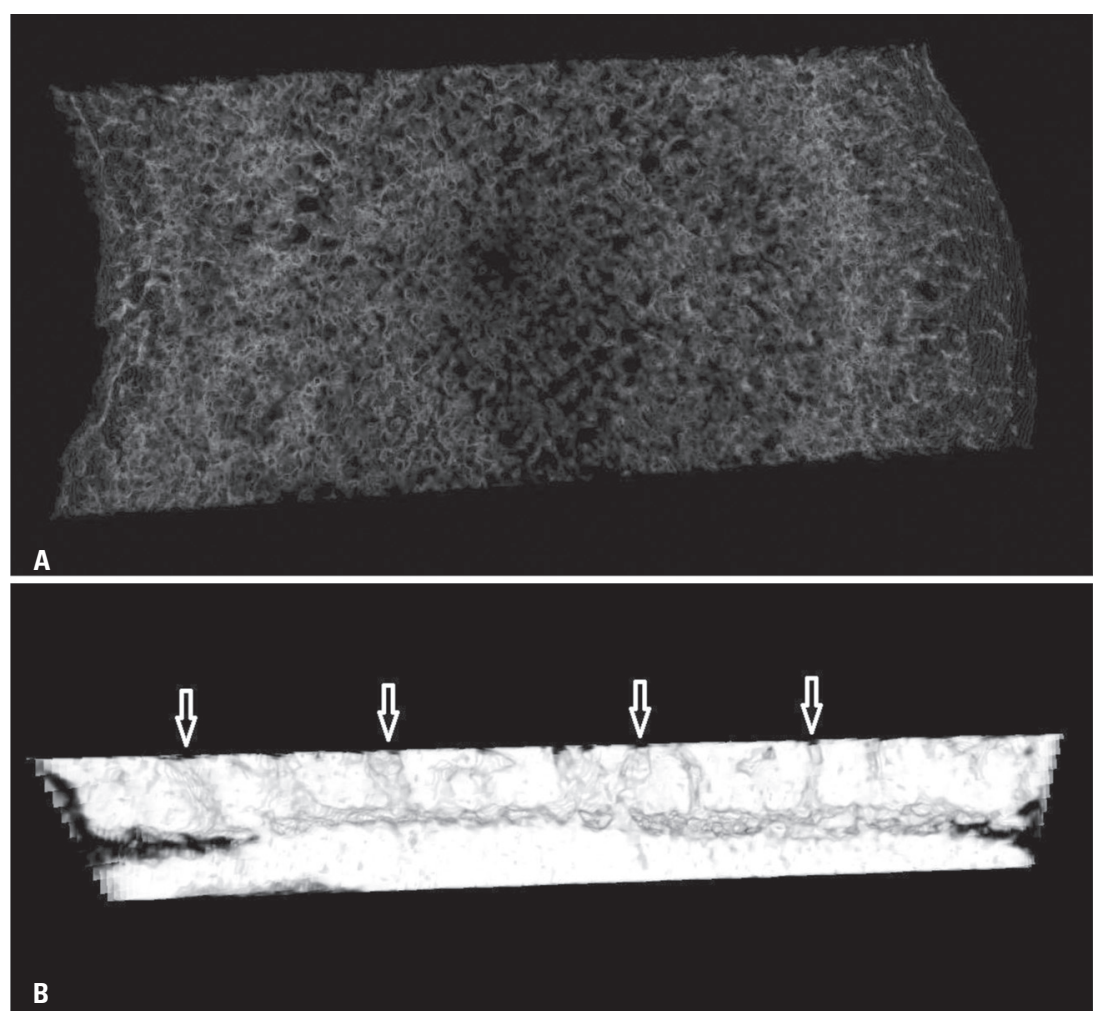

Figure 1. Micro-computed tomography virtual reconstruction of endplate: intervertebral disc junction; $\mathbf{A}$. Endplate viewed from the side of the disc. Numerous holes of different sizes can be seen; B. Midsagittal section: above — endplate with several marrow contact channels (marked with white arrows); below — intervertebral disc with no marrow contact channels penetrating its core.

from 5 frames. Scanning was performed perpendicular to the cranial-caudal axis of the sample, which was mounted on a custom plasticine attachment (this allowed for precise repositioning of the specimen along the $z$-axis with minimal rotational error) $[27,28]$.

\section{D sample reconstruction}

Virtual reconstructions were prepared using NRecon software (SkyScan). Each reconstructed cross-section had a resolution of $2000 \times 2000$ pixels. CTVox was used for primary volume rendering of every sample. The transfer function was appropriately set to visualise canals (empty spaces) inside the sample.

The 3-dimensional (3D) analysis was performed using CTVox, CTAnalyser and CTVol (SkyScan) applications. Before analysis, all cross-sections were binarised using CTAnalyser software to reconstruct virtual solid 3D models of the sample. These models were visualised in CTVol software (Fig. 1A, B).

\section{Image analysis}

From all images the number, calibre, diameter and distribution of endplate openings were measured using ImageJ [18]. Following the recommendations of Benneker et al. [1] we decided to neglect all holes smaller than $10 \mu \mathrm{m}$ in diameter, as these were found to be mostly artefacts. Images from both the cranial and caudal endplates were acquired and analysed. Each endplate was divided into 5 regions - anterior outer annulus (AO), anterior inner annulus (Al), $N P$, posterior inner annulus (PI), and posterior outer annulus (PO). The number of MCCs was counted per $10 \mathrm{~mm}^{2}$.

\section{IVD and endplate degeneration assessment}

Directly after microCT scanning, each sample was sectioned along the midsagittal plane for macroscopic IVD degeneration scoring according to Thompson's classification [30]. Each specimen was assessed by two of the authors, and the grade was averaged. Next, the samples were placed in a $10 \%$ solution of formaldehyde ( $\mathrm{pH}$ 7.4) for a minimum of 14 days.

Microscopic IVD and endplate degeneration was assessed using Boos's classification [4]. Tissue samples acquired from the midsagittal plane (of each of the 5 IVD regions) were dehydrated, embedded in paraffin, sectioned at $4 \mu \mathrm{m}$, and stained with haematoxylin and eosin (H\&E), Masson-Goldner trichrome and al- 

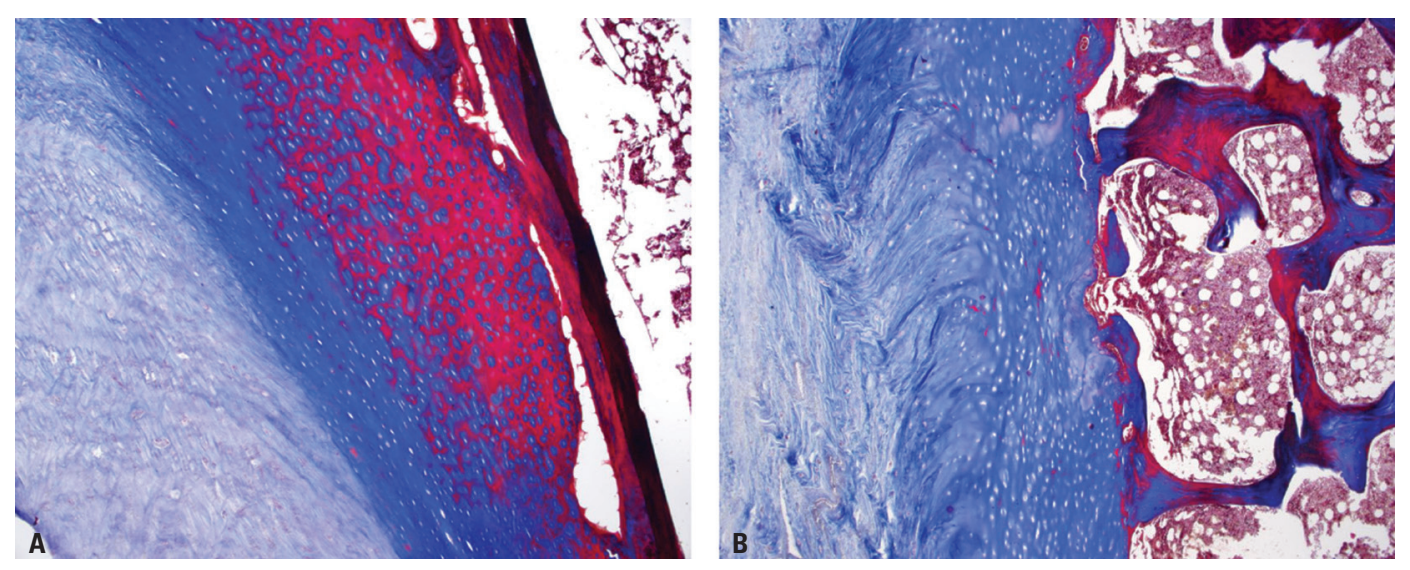

Figure 2. Histological slide: Masson-Goldner trichrome staining, magnification $\times 100$. Midsagittal section showing, from the left intervertebral disc connective tissue, cartilaginous endplate with chondrocyte holes, and lamellar bone with bone marrow; A. 70-year-old male, significant calcification (red) of the endplate; B. 30-year-old male, only slight endplate calcification can be seen.

cian blue-PAS (Department of Pathology, Jagiellonian University Medical College). Each sample was assessed and scored, using light microscopy, by two observers, and the final score per sample was averaged.

The degree of endplate calcification was analysed as the percentage of calcified tissue (red on Masson-Goldner trichrome staining) (Fig. 2A) to the non-calcified part (Fig. 2B). The fact of endplate calcification was verified on corresponding H\&E stained samples. The percentage of calcification was averaged for all examined endplate regions [31].

\section{Ethics}

The research protocol was approved by the Jagiellonian University Medical College Ethics Committee (registry number KBET/319/B/2012). The study has been performed in accordance with the ethical standards laid down in the 1964 Declaration of Helsinki and its later amendments. The specimen excision method was chosen so as not to destabilise the cadaver's spinal column.

\section{Statistical analysis}

Statistical analysis was conducted using Statistica 10.0 PL (Statsoft). Elements of descriptive statistics were used (mean, standard deviation [SD] percentage distribution). Differences between groups were tested with $t$ test, Mann-Whitney $U$ test or analysis of variance (ANOVA) as appropriate. To assess the correlation between scores, Pearson's correlation was used. Backward elimination was applied $(p>0.1)$ to identify the MCC size ranges that correlated best with endplate degeneration scored using Boos's classification [2]. Statistical significance was set at $p<0.05$.

\section{RESULTS}

The study group comprised 30 female and 30 male IVDs. The mean age \pm SD of the specimens was $51.4 \pm 19.5$. The basic characteristics of the study group are shown in Table 1.

IVD degeneration, graded using Thompson's classification, significantly correlated with Boos's IVD degeneration score $(r=0.77 ; p<0.0001)$. IVD and endplate degeneration, graded using Boos's score also strongly correlated with each other $(r=0.96$; $\mathrm{p}<0.0001$ ).

Specimen's age strongly correlated with both IVD degeneration (Thompson's and Boos's) and endplate degeneration (Boos's score), as well as the averaged percentage of endplate calcification $(r=0.76 ; r=0.77$; $r=0.73 ; r=0.75$, respectively; $p<0.0001)$. Age also showed a strong negative correlation with the total number of endplate openings $(r=-0.68 ; p<0.0001)$, as well as the number of openings (averaged from all endplate regions) of varying diameters $(r=-0.33-$ $(-0.76) ; p<0.0001)$, with the exception of openings over $300 \mu \mathrm{m}$ in diameter $(r=0.66 ; \mathrm{p}<0.0001)$ (Fig. 3). The number of the $300 \mu \mathrm{m}$ endplate openings negatively correlated with the number of all other openings $(r=-0.62-(-0.82) ; p<0.0001)$. This correlation was strongest for openings $10-50 \mu \mathrm{m}$ in diameter $(r=-0.82 ; p<0.0001)$. Figure 3 shows the age-distribution of endplate openings of different sizes among both sexes.

A similar relationship between the number of endplate openings and IVD and endplate degeneration/ /calcification was seen (Table 2). Figure 4 shows the number of endplate openings grouped according to Thompson's grade of degeneration. 
Table 1. Basic characteristics of the study group

\begin{tabular}{|c|c|c|c|c|}
\hline Parameters & Female $(n=30)$ & Male $(n=30)$ & Total $(n=60)$ & $\mathbf{P}^{*}$ \\
\hline Age (SD) & $52.8(19.8)$ & $50.0(19.4)$ & $51.4(19.5)$ & 0.57 \\
\hline IVD degeneration: Thompson's classification (SD) & $2.6(1.3)$ & $3.2(1.3)$ & $2.9(1.3)$ & 0.08 \\
\hline IVD degeneration: Boos's classification (SD) & $12.0(6.1)$ & $14.3(5.3)$ & $13.1(5.8)$ & 0.13 \\
\hline Endplate degeneration: Boos's classification (SD) & $8.9(5.3)$ & $11.5(4.8)$ & $10.2(5.2)$ & 0.06 \\
\hline Endplate calcification (\%) & $28.4(25.1)$ & $44.1(26.0)$ & $36.2(26.5)$ & 0.02 \\
\hline Number of endplate openings $(10-50 \mu \mathrm{m})^{* *}$ & $40.6(9.3)$ & $35.7(11.5)$ & $38.2(10.6)$ & 0.07 \\
\hline Number of endplate openings $(50-100 \mu \mathrm{m})^{* *}$ & $16.9(4.7)$ & $16.5(5.7)$ & $16.7(5.2)$ & 0.75 \\
\hline Number of endplate openings $(100-300 \mu \mathrm{m})^{* *}$ & $12.3(2.7)$ & $12.9(4.1)$ & $12.6(3.4)$ & 0.55 \\
\hline Number of endplate openings $(>300 \mu \mathrm{m})^{* *}$ & $6.0(2.7)$ & $6.2(3.3)$ & $6.1(3.0)$ & 0.77 \\
\hline Number of endplate openings (total) ${ }^{* *}$ & $75.8(13.1)$ & $71.3(17.9)$ & $73.6(15.7)$ & 0.26 \\
\hline Number of endplate openings under NP $(10-50 \mu \mathrm{m})^{* * *}$ & $61.2(18.2)$ & $51.6(18.8)$ & $56.4(19.0)$ & 0.047 \\
\hline
\end{tabular}

${ }^{*}$ For differences between females and males; ** 0 pening density per $10 \mathrm{~mm}^{2}$ of endplate area, averaged from all endplate regions (sizes represent opening diameter); ${ }^{* * *}$ 0pening density per $10 \mathrm{~mm}^{2}$ of endplate area, number of openings given only for the endplate region underlying the nucleus pulposus (sizes represent opening diameter); IVD — intervertebral disc; $\mathrm{NP}$ — nucleus pulposus; $\mathrm{SD}$ - standard deviation

By backward elimination we have determined that openings $10-50 \mu \mathrm{m}$ in diameter $(r=-0.91$; $p<0.0001$ ) accounted for $85 \%$ of the variability in the "total number of endplate openings - degree of endplate degeneration" $(r=-0.85 ; p<0.0001)$ correlation.

\section{DISCUSSION}

This study aimed at revealing the relationships between cervical IVD degeneration, endplate calcification, and the patency of endplate MCCs. The major finding presented in this manuscript is the fact that there is a strong negative correlation between the number of endplate MCCs, and both macroscopic and microscopic cervical IVD and endplate degeneration. Similar to lumbar IVDs [1], this study has also shown that the relationship between MCC closure and IVD degeneration was the strongest for the region corresponding to the NP. This corresponds well with what was written earlier, that the central portion of the endplate is responsible for the diffusion of the majority of nutritional substances $[22,24]$.

This study is the first to use microCT together with histological analysis to allow for the localisation, quantification, and characterisation of MCCs in the cervical endplate. Up-to-date only one similar study [1] explored such a relationship in lumbar IVDs, using scanning electron microscopy (SEM). Other studies assessing this relationship based solely on histological analysis [7], which allows only visualising a certain portion of the endplate, and not its entire structure. The method used in the current study is easily repro- ducible - both through the use of microCT, and also due to the fact that both Thompson's and Boos's grading systems were tested for interobserver reliability, practicability, and validity [14]. All the above mentioned allow to perform accurate measurements of endplate MCCs. This study has also brought to light the fact that, if used properly, Thompson's grade of IVD degeneration closely correlates with Boos's score of microscopic IVD and endplate degeneration. This gives clinicians performing cervical spine surgeries a useful tool to support their post-operative discussion with their patients, when the results of pathological analysis are not yet known.

In opposition to the study by Benneker et al. [1] our findings showed a strong correlation between age and the decreasing number of MCCs (Fig. 3), with the exclusion of openings larger than $300 \mu \mathrm{m}$. The strong correlation between IVD degeneration and the decreasing number of endplate openings has been noted before $[1,20]$ but only for lumbar IVD's. Figure 3 also points to an important fact that the age at which the number of MCCs decreases can vary considerably between individuals. This has been reported before for lumbar IVDs $[1,4]$.

The lack of correlation between the total area of all endplate openings, both averaged and divided by region, and endplate or IVD degeneration grade can be partially explained by the fact that with increasing endplate degeneration there was a significant increase in the number of endplate openings larger than $300 \mu \mathrm{m}$ (largest noted were $\sim 600 \mu \mathrm{m}$ in diameter). Based on our results and the SEM findings of 

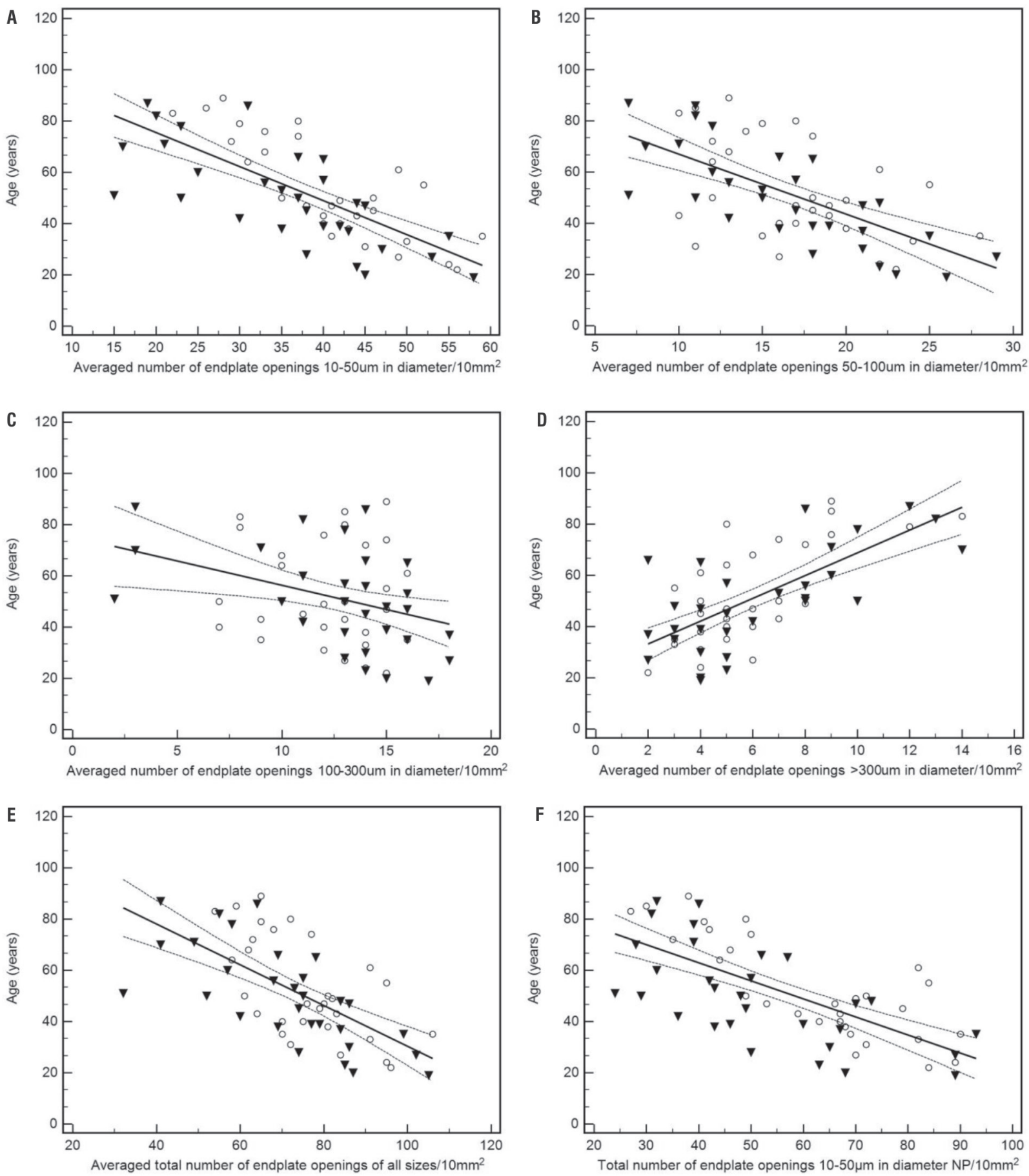

Figure 3. Scatter diagram of age vs. number endplate openings of different sizes among both sexes. The black line represents the regression line. The dash line is the $95 \%$ confidence interval. The white circles represent female specimens and the black triangles represent male specimens; A. Age vs. total number of endplate openings $10-50 \mu \mathrm{m}$ in diameter averaged from all endplate regions $/ 10 \mathrm{~mm}^{2}$; B. Age vs. total number of endplate openings $50-100 \mu \mathrm{m}$ in diameter averaged from all endplate regions $/ 10 \mathrm{~mm}^{2}$; C. Age vs. total number of endplate openings $100-300 \mu \mathrm{m}$ in diameter averaged from all endplate regions $/ 10 \mathrm{~mm}^{2}$; D. Age vs. total number of endplate openings $>300 \mu \mathrm{m}$ in diameter averaged from all endplate regions $/ 10 \mathrm{~mm}^{2} ; \mathbf{E}$. Age vs. total number of endplate openings of all sizes averaged from all endplate regions $/ 10 \mathrm{~mm}^{2}$; F. Age vs. total number of endplate openings $10-50 \mu \mathrm{m}$ in diameter underlying the nucleus pulposus (NP) only/10 mm².

Benneker et al. [1], we concur that the increased size of the openings was caused by endplate cracking during degeneration. These openings do not contain capillary buds [5], and are the offspring of age-associated endplate thinning, clefts and fissures [4]. 
Table 2. Correlations between Thompson's and Boos's degeneration scores and endplate calcification (\%), and the number of endplate openings of varying sizes

\begin{tabular}{|c|c|c|c|c|}
\hline Number of endplate openings & $\begin{array}{l}\text { Thompson's IVD } \\
\text { degeneration score }\end{array}$ & $\begin{array}{c}\text { Boos's IVD } \\
\text { degeneration score }\end{array}$ & $\begin{array}{c}\text { Boos's endplate } \\
\text { degeneration score }\end{array}$ & $\begin{array}{c}\text { Endplate } \\
\text { calcification }(\%)\end{array}$ \\
\hline $10-50 \mu \mathrm{m}^{*}$ & $\begin{array}{l}r=-0.94 \\
p<0.0001\end{array}$ & $\begin{array}{l}r=-0.90 \\
p<0.0001\end{array}$ & $\begin{aligned} r & =-0.91 \\
p & <0.0001\end{aligned}$ & $\begin{array}{l}r=-0.93 \\
p<0.0001\end{array}$ \\
\hline $50-100 \mu \mathrm{m}^{*}$ & $\begin{aligned} r & =-0.83 \\
p & <0.0001\end{aligned}$ & $\begin{aligned} r & =-0.77 \\
p & <0.0001\end{aligned}$ & $\begin{aligned} r & =-0.79 \\
p & <0.0001\end{aligned}$ & $\begin{aligned} r & =-0.79 \\
p & <0.0001\end{aligned}$ \\
\hline $100-300 \mu \mathrm{m}^{*}$ & $\begin{array}{l}r=-0.54 \\
p<0.0001\end{array}$ & $\begin{aligned} r & =-0.51 \\
p & <0.0001\end{aligned}$ & $\begin{aligned} r & =-0.51 \\
p & <0.0001\end{aligned}$ & $\begin{array}{l}r=-0.51 \\
p<0.0001\end{array}$ \\
\hline$>300 \mu \mathrm{m}^{*}$ & $\begin{array}{c}r=0.79 \\
p<0.0001\end{array}$ & $\begin{array}{c}r=0.78 \\
p<0.0001\end{array}$ & $\begin{array}{c}r=0.72 \\
p<0.0001\end{array}$ & $\begin{array}{c}r=0.79 \\
p<0.0001\end{array}$ \\
\hline Total $^{*}$ & $\begin{aligned} r & =-0.88 \\
p & <0.0001\end{aligned}$ & $\begin{aligned} r & =-0.83 \\
p & <0.0001\end{aligned}$ & $\begin{aligned} r & =-0.85 \\
p & <0.0001\end{aligned}$ & $\begin{aligned} r & =-0.85 \\
p & <0.0001\end{aligned}$ \\
\hline Under NP $(10-50 \mu \mathrm{m})^{* *}$ & $\begin{aligned} r & =-0.95 \\
p & <0.0001\end{aligned}$ & $\begin{array}{l}r=-0.92 \\
p<0.0001\end{array}$ & $\begin{array}{l}r=-0.94 \\
p<0.0001\end{array}$ & $\begin{aligned} r & =-0.94 \\
p & <0.0001\end{aligned}$ \\
\hline
\end{tabular}

*Opening density per $10 \mathrm{~mm}^{2}$ of endplate area, averaged from all endplate regions (sizes represent opening diameter); **0pening density per $10 \mathrm{~mm}^{2}$ of endplate area, number of openings given only for the endplate region underlying the nucleus pulposus (sizes represent opening diameter); IVD — intervertebral disc; NP — nucleus pulposus

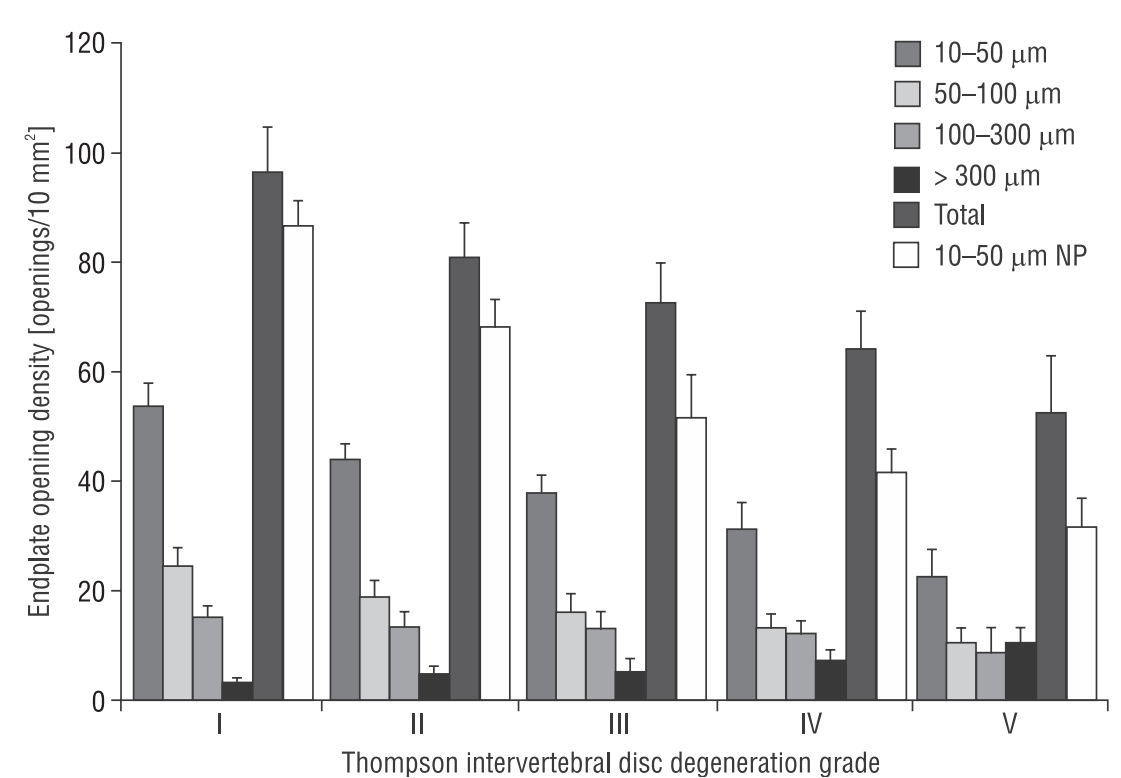

Figure 4. The number of endplate openings grouped according to Thompson's grading. 10-50 $\mu \mathrm{m} ; 50-100 \mu \mathrm{m} ; 100-300 \mu \mathrm{m} ;>300 \mu \mathrm{m}$; Total — opening density per $10 \mathrm{~mm}^{2}$ of endplate area, averaged from all endplate regions (sizes represent opening diameter). "Total" referring to the added number of endplate openings of all sizes, averaged from all endplate regions. 10-50 $\mu$ m nucleus pulposus (NP) — opening density per $10 \mathrm{~mm}^{2}$ of endplate area, number of openings given only for the endplate region underlying the NP (sizes represent opening diameter).

Similarly to previous studies on lumbar IVD samples $[1,23]$, we have observed that the correlation between endplate degeneration and the number of endplate openings is the strongest for those MCCs that hold capillary buds [3]. However, in contrast to other studies, we have chosen to investigate openings $10-50 \mu \mathrm{m}$ in diameter, as animal studies report that capillary buds, within the endplate's cartilage can be between 5-50 $\mu \mathrm{m}$ in size [15]. However, as mentioned earlier, we did not include into our analysis openings smaller than $10 \mu \mathrm{m}$, as they have been found to be mostly artefacts [1]. The vascular buds are capillary structures, morphologically similar among humans, monkeys, and rabbits [36]. Capillaries can be classified into three types - discontinuous, fenestrated, and continuous. Capillary permeability increases in this order, and the morphological features of the endothelium indicate organ specificity [2]. The vascular buds were found to be fenestrated capillaries, which are usually observed in metabolically very active tissues 
such as endocrine glands, kidneys, intestinal mucosa and dorsal root ganglion $[15,16]$. This would mean that there is enhanced permeability and metabolism in both the cartilaginous endplate and the IVD.

This study points out important correlations between endplate calcification, MCC occlusion and IVD degeneration. However, the exact mechanisms by which the endplate calcifies are yet to be discovered. Several factors are thought to play a role in the pathogenesis of endplate calcification e.g. calcium-binding collagen type X [3], ankyrin [37], ENPP1 and TGF-beta1 [35]. We cannot state for certain, as this study does not answer cause and effect questions, but one could presume that endplate calcification is rather the cause, than the effect of a fall in nutrient transport, as it begins in the well-vascularised centre of the endplate, and not in the outer regions where the number of endplate openings is lower.

In our study, we have not decided to go beyond microCT and histological analysis, even though some studies $[1,20,26]$ reached out for biochemical parameters to supplement their search for the cause of endplate-IVD degeneration. This is something worth exploring in future studies, as different studies $[1,20,26]$ produce conflicting results - especially when it comes to the role of glycosaminoglycans in the interplay between age, endplate bone porosity and IVD degeneration. Rodriguez et al. [26] observed that endplate porosity increased with age while glycosaminoglycan content decreased. This conflicts with the study by Nachemson et al. [20] which showed a decrease in endplate porosity with age and degeneration. The findings of Nachemson et al. [20] are also supported by the result obtained by Benneker et al. [1] as well as the present study.

\section{CONCLUSIONS}

Concluding, this is the first study to perform such an investigation on human cervical spine samples. It has brought to light that, similarly to lumbar IVDs, there is a strong negative correlation between the number of endplate MCCs, and both macroscopic and microscopic cervical IVD and endplate degeneration. This could further support the idea that endplate calcification, through the occlusion of MCCs, leads to a fall in nutrient transport to the IVD, and subsequently causes its degeneration. Additionally, the method demonstrated in this study allows performing accurate and easily reproducible measurements of the number, size and shape of endplate MCCs. What is more, we have shown that Thompson's classification corresponds well to Boos's histological classification of endplate and IVD degeneration, allowing the use of Thompson's classification as a surrogate of microscopic degeneration, until the results of pathological analysis are known.

\section{ACKNOWLEDGEMENTS}

This study was funded by the National Science Centre, Poland under grant number DEC-2012/07/N/ /NZ5/00078. Krzysztof A. Tomaszewski received a scholarship to prepare his $\mathrm{PhD}$ thesis from the $\mathrm{Na}$ tional Science Centre, Poland under award number DEC-2013/08/T/NZ5/00020.

\section{AUTHOR CONTRIBUTION}

Design and planning of the study - KAT, DA, RT, JAW. Sample collection - KAT, TK. Sample preparation - KAT, RT. Histological analysis - KAT, DA, RT. Data interpretation - KAT, RT, DA, JAW (sample measurement and result verification), KAT (statistical analysis). Bibliographic search - KAT. Drafting and revising the manuscript - KAT. Obtaining funding - KAT. Critical revision of the manuscript - DA, TK, RT, JAW. All authors have read and approved the final version of the manuscript.

All co-authors confirm the above-mentioned contributions and consent to the fact that this study is a part of Krzysztof A. Tomaszewski's PhD thesis. The co-authors confirm that Krzysztof A. Tomaszewski has contributed significantly ( $80 \%$ in total) to every part of this study, as stated above.

\section{REFERENCES}

1. Benneker LM, Heini PF, Alini M, Anderson SE, Ito K (2005) 2004 Young Investigator Award Winner: vertebral endplate marrow contact channel occlusions and intervertebral disc degeneration. Spine (Phila Pa 1976), 30: 167-173.

2. Bennett HS, Luft JH, Hampton JC (1959) Morphological classification of vertebrate blood capillaries. Am J Physiol, 196: 381-390.

3. Boos N, Nerlich AG, Wiest I, von der Mark K, Aebi M (1997) Immunolocalization of type $X$ collagen in human lumbar intervertebral discs during ageing and degeneration. Histochem Cell Biol 108: 471-480.

4. Boos N, Weissbach S, Rohrbach H, Weiler C, Spratt KF, Nerlich AG (2002) Classification of age-related changes in lumbar intervertebral discs. Volvo Award in basic science. Spine, 27: 2631-2644.

5. Coventry MB, Ghormley RK, Kernohan JW (1945) The intervertebral disc: its microscopic anatomy and pathology: Part II. Changes in the intervertebral disc concomitant with age. J Bone Joint Surg Am, 27: 233-247. 
6. Edwards WT, Zheng Y, Ferrara LA, Yuan HA (2001) Structural features and thickness of the vertebral cortex in the thoracolumbar spine. Spine (Phila Pa 1976), 26: 218-225.

7. Grignon B, Grignon $Y$, Mainard D, Braun M, Netter P, Roland J (2000) The structure of the cartilaginous end-plates in elder people. Surg Radiol Anat, 22: 13-19.

8. Hangai M, Kaneoka K, Kuno S, Hinotsu S, Sakane M, Mamizuka N, Sakai S, Ochiai N (2008) Factors associated with lumbar intervertebral disc degeneration in the elderly. Spine J, 8: 732-740.

9. Horner HA, Urban JP (2001) 2001 Volvo Award Winner in Basic Science Studies: Effect of nutrient supply on the viability of cells from the nucleus pulposus of the intervertebral disc. Spine (Phila Pa 1976), 26: 2543-2549.

10. Huang CY, Gu WY (2008) Effects of mechanical compression on metabolism and distribution of oxygen and lactate in intervertebral disc. J Biomech, 41: 1184-1196.

11. Ishihara H, Urban JP (1999) Effects of low oxygen concentrations and metabolic inhibitors on proteoglycan and protein synthesis rates in the intervertebral disc. J Orthop Res, 17: 829-835.

12. Jackson AR, Huang CY, Brown MD, Gu WY (2011) 3D finite element analysis of nutrient distributions and cell viability in the intervertebral disc: effects of deformation and degeneration. J Biomech Eng, 133: 091006.

13. Jackson AR, Huang CY, Gu WY (2011) Effect of endplate calcification and mechanical deformation on the distribution of glucose in intervertebral disc: a 3D finite element study. Comput Methods Biomech Biomed Engin, 14: 195-204.

14. Kettler A, Wilke HJ (2006) Review of existing grading systems for cervical or lumbar disc and facet joint degeneration. Eur Spine J, 15: 705-718.

15. Kobayashi S, Baba H, Takeno K, Miyazaki T, Uchida K, Kokubo Y, Nomura E, Morita C, Yoshizawa H, Meir A (2008) Fine structure of cartilage canal and vascular buds in the rabbit vertebral endplate. Laboratory investigation. J Neurosurg Spine, 9: 96-103.

16. Kobayashi S, Yoshizawa H (2002) Effect of mechanical compression on the vascular permeability of the dorsal root ganglion. J Orthop Res, 20: 730-739.

17. Le Maitre CL, Freemont AJ, Hoyland JA (2005) The role of interleukin-1 in the pathogenesis of human intervertebral disc degeneration. Arthritis Res Ther, 7: R732-745.

18. Mizia E, Tomaszewski KA, Lis GJ, Goncerz G, Kurzydło W (2012) The use of computer-assisted image analysis in measuring the histological structure of the human median nerve. Folia Morphol, 71: 82-85.

19. Moore RJ (2006) The vertebral endplate: disc degeneration, disc regeneration. Eur Spine J, 15: S333-\$337.

20. Nachemson A, Lewin T, Maroudas A, Freeman MA (1970) In vitro diffusion of dye through the end-plates and the annulus fibrosus of human lumbar inter-vertebral discs. Acta Orthop Scand, 41: 589-607.

21. Nerlich AG, Boos N, Wiest I, Aebi M (1998) Immunolocalization of major interstitial collagen types in human lumbar intervertebral discs of various ages. Virchows Arch, 432: 67-76.

22. Ogata K, Whiteside LA (1981) 1980 Volvo award winner in basic science. Nutritional pathways of the intervertebral disc. An experimental study using hydrogen washout technique. Spine, 6: 211-216.

23. Oki S, Matsuda $Y$, Itoh T, Shibata T, Okumura H, Desaki J (1994) Scanning electron microscopic observations of the vascular structure of vertebral endplates in rabbits. J Orthop Res, 12: 447-449.

24. Raj PP (2008) Intervertebral disc: anatomy-physiology-pathophysiology-treatment. Pain Pract, 8: 18-44.

25. Roberts S, Urban JPG, Evans H, Eisenstein SM (1996) Transport properties of the human cartilage end-plate in relation to its composition and calcification. Spine, 21: 415-420.

26. Rodriguez $A G$, Slichter $C K$, Acosta FL, Rodriguez-Soto $A E$, Burghardt AJ, Majumdar S, Lotz JC (2011) Human disC nucleus properties and vertebral endplate permeability. Spine (Phila Pa 1976), 36: 512-520.

27. Skrzat J, Kozerska M, Wróbel A (2014) Micro-computed tomography study of the abnormal osseous extensions of sella turcica. Folia Morphol, 73: 19-23.

28. Skrzat J, Leszczyński B, Kozerska M, Wróbel A (2013) Topography and morphometry of the subarcuate canal. Folia Morphol, 72: 357-361.

29. Taylor JR, Twomey LT (1998) Growth of human intervertebral discs and vertebral bodies. J Anat, 120: 49-68.

30. Thompson JP, Pearce RH, Schechter MT, Adams ME, Tsang IK, Bishop PB (1990) Preliminary evaluation of a scheme for grading the gross morphology of the human intervertebral disc. Spine, 15: 411-415.

31. Tomaszewski KA, Adamek D, Pasternak A, Głowacki R, Tomaszewska R, Walocha JA (2014) Degeneration and calcification of the cervical endplate is connected with a decreased expression of ANK, ENPP- 1 , OPN and TGF- $\beta 1$ in the intervertebral disc. Pol J Pathol, 65: 204-211.

32. Urban JP, Smith S, Fairbank JC (2004) Nutrition of the intervertebral disc. Spine (Phila Pa 1976), 29: 2700-2709.

33. Urban MR, Fairbank JC, Etherington PJ, Loh FRCA L, Winlove CP, Urban JP (2001) Electrochemical measurement of transport into scoliotic intervertebral discs in vivo using nitrous oxide as a tracer. Spine (Phila Pa 1976), 26: 984-990.

34. van der Werf M, Lezuo $P$, Maissen $O$, van Donkelaar CC, Ito $K$ (2007) Inhibition of vertebral endplate perfusion results in decreased intervertebral disc intranuclear diffusive transport. J Anat, 211: 769-774.

35. Xu HG, Hu CJ, Wang H, Liu P, Yang XM, Zhang Y, Wang LT (2011) Effects of mechanical strain on ANK, ENPP1 and TGF-beta1 expression in rat endplate chondrocytes in vitro. Mol Med Rep, 4: 831-835.

36. Yoshizawa H, Ohiwa T, Kubota K (1986) Morphological study on the vertebral route for the nutrition of the intervertebral disc. Neuro-Orthopedics. 1: 17-32.

37. Zaka R, Williams CJ (2006) Role of the progressive ankylosis gene in cartilage mineralization. Curr Opin Rheumatol, 18: 181-186. 